\title{
ÉPOCA DE SOBRESSEMEADURA DE GRAMÍNEAS ANUAIS DE INVERNO E DE VERÃO NO CAPIM-TIFTON 85: VALOR NUTRITIVO ${ }^{1}$
}

\author{
Tifton 85 overseeded with differnt seasons species: Nutritive value
}

\author{
Andréia Luciane Moreira², Ricardo Andrade Reis ${ }^{3}$, Flávia Fernanda Simili4, Márcio dos Santos Pedreira ${ }^{5}$, \\ Marcella de Toledo Piza Roth ${ }^{6}$, Ana Cláudia Ruggieri ${ }^{7}$
}

\begin{abstract}
RESUMO
Conduziu-se o experimento na UNESP-Jaboticabal, no período de inverno-primavera-verão de 2001-2002, objetivando determinar os teores de proteína bruta (PB), parede celular (FDN, FDA, lignina, celulose e hemicelulose) e a digestibilidade in vitro da matéria orgânica (DIVMO) no capim-Tifton 85 exclusivo e sobressemeado com aveia preta, milheto e sorgo-sudão. Os tratamentos testados foram: milheto+aveia preta; AG2501C+aveia preta, sobressemeados nas áreas de Tifton-85, em 19-06 ou 02-07-2002, e capim-Tifton 85 (Testemunha). O delineamento experimental foi de blocos casualizados, com três repetições. Os teores de PB foram maiores na primeira avaliação quando comparada às demais. Observou-se aumento nos teores de FDN, FDA e lignina, e comportamento inverso nos valores de DIVMO, em relação aos períodos de crescimento, nas duas épocas de semeadura. Os teores avaliados de PB, parede celular e DIVMO apresentaram variação em função da composição botânica e morfológica, no decorrer das avaliações e épocas de semeadura.
\end{abstract}

Termos para indexação: Aveia preta, constituintes da parede celular, digestibilidade in vitro da matéria orgânica, proteína bruta, triticale.

\begin{abstract}
The experiment was conducted at UNESP-Jaboticabal on the 2001-2002 winter-spring-summer period to evaluate the crude protein, cell wall (NDF, ADF, cellulose, hemicellulose and lignin) contents, and in vitro organic matter digestibility (IVOMD) of the Tifton 85 alone or overseeded with annual species (oat, pearl millet, and sorghum Sudan grass-SS). It was evaluated the followings treatments: pearl millet plus bristal oat; SS AG2501 C plus bristeal oat, overseeded on Tifton 85 area on 06/19/02, or 07/02/02, and Tifton 85. The data were analyzed according a randomized block design with three repetitions. The $\mathrm{CP}$ was highest on the forage harvested at the first evaluation. The cell wall content increased, and IVOMD decreased, in relation to the plant development in booth seeding time. The CP, cell wall contents, and IVOMD changed during the evaluations and seeding time due to the botanical and plants morphological composition.
\end{abstract}

Index terms: Bristeal oat, cell wall, In vitro organic matter digestibility, crude protein.

(Recebido para publicação em 20 de outubro de 2005 e aprovado em 16 de fevereiro de 2006)

\section{INTRODUÇÃO}

A sobressemeadura de espécies forrageiras de inverno, em áreas formadas com espécies perenes de clima tropical, é uma opção a ser considerada para aumentar a produção e sua distribuição estacional. Além disso, tem-se a possibilidade de aumentar o valor nutritivo $(\mathrm{VN})$ da forragem durante a estação fria e seca do ano, pois visam combinar os picos de produção de massa seca que são atingidos em diferentes épocas, de acordo com a espécie, resultando no aumento da produção e do período de utilização da pastagem (ROSO et al., 1999) e melhoria do VN da forragem ofertada (LUPATINI, 2000; REIS et al., 2001).

A composição química da planta forrageira é um dos parâmetros utilizados para medir seu VN. O baixo VN das forrageiras é freqüentemente mencionado na literatura e está associado ao reduzido teor de proteína bruta (PB) e minerais, e ao alto conteúdo de parede celular (lignina, celulose, hemicelulose, cutícula e sílica), e, conseqüentemente, decréscimos na digestibilidade são esperados (SOEST, 1994).

Ao avaliarem os efeitos da sobressemeadura de espécies de inverno (centeio, azevém, trevos vermelho e encarnado) em áreas de capim-Tifton 85 ,

\footnotetext{
1 Parte da Tese de Doutorado do primeiro autor, projeto financiado pela FAPESP.

2 Pesquisadora do Pólo Regional Alta Sorocabana - Rod. Raposo Tavares, Km 561 - Cx. P. 298 - 19.001-970 - Presidente Prudente, SP aluciane@aptaregional.sp.gov.br

${ }_{3}$ Professor da FCAV/UNESP - Via de acesso Prof. Paulo D. Castellane s/n - 14.884-900 -Jaboticabal, SP - Pesquisador CNPq-rareis@fcav.unesp.br

${ }^{4}$ Pesquisadora do Pólo Centro Leste - Anel Viário, Km 321- Cx. P. 271 - 14001-970 - Ribeirão Preto, SP - flaviasimili@aptaregional.sp.gov.br

${ }^{5}$ Professor DTRA/UESB - Departamento de Tecnologia Rural e Animal - Universidade Estadual Sudoeste da Bahia - Praça da Promavera, 40 -

Bairro Primavera - 45.700-000 - Itapetinga, BA - pedreira@fcav.unesp.br

${ }^{6}$ Graduanda em Zootecnia da FCAV/UNESP Via de acesso Prof. Paulo D. Castellane s/n - 14.884-900 - Jaboticabal, SP.

${ }^{7}$ Pesquisadora do Instituto de Zootecnia - Rodovia Carlos Tonanni, Km 94 - Cx. P. 63 - 14.160-970 - Sertãozinho, SP - ruggieri@iz.sp.gov.br
} 
Reis et al. (2001) observaram elevado teor de PB $(14,9 \%)$ e DIVMO $(65,0 \%)$ da forragem disponível nas áreas de capim-Tifton 85 cultivadas com espécies de inverno. $\mathrm{Na}$ amostragem de verão, observou-se aumento nos teores de FDN $(81,4 \%)$ e diminuição nos de PB $(8,5 \%)$ e nos valores de DIVMO $(58,5 \%)$, que pode ter ocorrido em função do desaparecimento das espécies de inverno.

Em experimento realizado por Zago \& Ribas (1989), avaliando o valor nutritivo das forrageiras sob corte, foram registrados teores de 17,4; 16,7 e 18,4\% de PB e 60,2; 59,2 e $72,1 \%$ de DIVMS, respectivamente, na cultivar AG2501C, milheto e aveia.

Objetivou-se com este trabalho avaliar os teores de proteína bruta, parede celular e a digestibilidade in vitro da matéria orgânica do capim-Tifton 85 exclusivo ou sobressemeado com espécies de inverno e verão.

\section{MATERIAL E MÉTODOS}

O experimento foi conduzido no setor de Forragicultura da Faculdade de Ciências Agrárias e Veterinárias de Jaboticabal-UNESP, em área com aproximadamente $1.200 \mathrm{~m}^{2}$, situada em solo classificado como Latossolo Vermelho-Escuro Distrófico típico textura argilosa (ANDRIOLI \& CENTURION, 1999), constituída de 18 parcelas. Cada parcela foi constituída de $40 \mathrm{~m}^{2}(10 \mathrm{~m}$ $\mathrm{x} 4 \mathrm{~m}$ ), dispostos em três blocos. Os resultados da análise química de solo foram os seguintes: $\mathrm{pH}\left(\mathrm{CaCl}_{2}\right)=5,5 ; \mathrm{MO}$ $=28 \mathrm{~g} / \mathrm{dm}^{3} ; \mathrm{P}$ (resina) $=11 \mathrm{mg} / \mathrm{dm}^{3} ; \mathrm{K}^{+}=5,9 \mathrm{mmol} / \mathrm{dm}^{3}$; $\mathrm{Ca}^{2+}=38 \mathrm{mmol} / \mathrm{dm}^{3} ; \mathrm{Mg}^{2+}=14 \mathrm{mmol} / \mathrm{dm}^{3} ; \mathrm{H}+\mathrm{Al}=25$ $\mathrm{mmol} / \mathrm{dm}^{3} ; \mathrm{SB}=58 \mathrm{mmol} / \mathrm{dm}^{3} ; \mathrm{CTC}=83 \mathrm{mmol} / \mathrm{dm}^{3}, \mathrm{e}$ saturação por bases $=70 \%$.

Foram testados seis tratamentos: T1: Milheto (Pennisetum americanum (L.) Leeke) cv. BRS1501 + Aveia preta (Avena strigosa Schreb) cv. IAPAR 61, sobressemeados em 19-06; T2: AG2501C (Sorghum bicolor (L.) Moench x Sorghum sudanense (Piper) Stapf) cv. AG2501C + Aveia preta sobressemeados em 19-06; T3: Testemunha, capim-Tifton 85 (Cynodon nlemfuensis Vanderyst x Cynodon dactylon (L.) Pers) exclusivo; T4: Milheto + Aveia preta sobressemeados em 02-07; T5: AG2501C + Aveia preta sobressemeados em 02-07; T6: Testemunha, capim-Tifton 85 exclusivo. A escolha das espécies de verão foi com base na hipótese de que essas plantas germinassem e se desenvolvessem nos períodos de temperaturas mais altas, proporcionando melhoria na distribuição da massa de forragem.

A sobressemeadura foi realizada com semeadeira de plantio direto com o espaçamento de $22,5 \mathrm{~cm}$ entre linhas, utilizando-se $60 \mathrm{Kg}$ de sementes/ha de aveia preta e $16 \mathrm{Kg}$ de sementes/ha do milheto e de AG2501C. A taxa de semeadura nos tratamentos com as misturas das forrageiras de inverno foi calculada proporcionalmente.

Utilizou-se, na adubação inicial, de $30 \mathrm{Kg} / \mathrm{ha}$ de nitrogênio na forma de uréia; $60 \mathrm{Kg} / \mathrm{ha} \mathrm{de} \mathrm{P}_{2} \mathrm{O}_{5}$ na forma de superfosfato simples e $60 \mathrm{Kg} / \mathrm{ha}$ de $\mathrm{K}_{2} \mathrm{O}$ na forma de cloreto de potássio, respectivamente.

Após 30 dias da sobressemeadura, realizou-se a adubação de cobertura com $40 \mathrm{Kg} / \mathrm{ha}$ de $\mathrm{N}$ e $40 \mathrm{Kg} / \mathrm{ha} \mathrm{de}$ $\mathrm{K}_{2} \mathrm{O}$, utilizando-se como fonte de adubo a uréia e o cloreto de potássio.

$\mathrm{Na}$ área experimental, foi utilizada a irrigação por aspersão até o mês de agosto, aplicando-se uma irrigação de $60 \mathrm{~mm}$ de lâmina d'água por mês, visando a garantir uma adequada formação das forrageiras de inverno. A irrigação foi quantificada com base nos dados obtidos em experimentos anteriores realizados no setor de Forragicultura da FCAV/UNESP.

Os pastos foram manejados em sistema de lotação rotacionada, procedendo-se avaliação da massa de forragem e início do pastejo quando as plantas atingiram $55-60 \mathrm{~cm}$ de altura nas avaliações em que havia presença de forrageiras de inverno (primeira, segunda e terceira avaliações). Nas avaliações dos pastos que continham apenas o capim-Tifton 85 (quarta e quinta) adotou-se a altura de $35-40 \mathrm{~cm}$.

As amostragens foram realizadas antes da entrada dos animais na área através do corte manual das plantas, contida em um quadrado de $1 \mathrm{~m}^{2}$, a uma altura de $20 \mathrm{~cm}$ (primeira, segunda e terceira avaliações) e de $10 \mathrm{~cm}$ (ausência das forrageiras de inverno, quarta e quinta avaliações).

Após o corte, a área experimental foi dividida em faixas, delimitadas por cerca elétrica, sendo utilizadas vacas leiteiras da raça Holandesa no rebaixamento das forrageiras até as alturas acima preconizadas, adotando-se uma oferta média de forragem de $6 \%$ do peso dos animais. Após a saída dos animais, em todos os períodos de crescimento, foi realizada a adubação de cobertura, utilizando-se de 40 $\mathrm{Kg} / \mathrm{ha}$ de nitrogênio na forma de uréia.

Foram realizadas cinco avaliações referentes às duas épocas de semeadura (E), com os seguintes períodos de crescimento (C): C1E1: 19-06 a 06-08 (49 dias); C2E1: 0708 a 13-09 (38 dias); C3E1: 14-09 a 25-10 (42 dias), C4E1: 2610 a 09-12 (45 dias), C5E1: 10-12 a 15-01 (37 dias) e, C1E2: 02-07 a 19-08 (49 dias), C2E2: 20-08 a 1-10 (41 dias), C3E2: 02-10 a 11-11 (41 dias), C4E2: 12-11 a 07-01 (58 dias) e, C5E2: 08-01 a 11-02 (35 dias). 
A forragem colhida foi encaminhada ao Laboratório de Forragicultura e separada em plantas de inverno, de verão, capim-Tifton 85 , plantas invasoras e material morto. Após a separação de cada espécie, procedeu-se nova pesagem para avaliação da proporção da composição botânica dos pastos.

A seguir, retirou-se uma amostra de cada fração previamente separada e levada a secar em estufa de ventilação de ar forçada a $60^{\circ} \mathrm{C}$. Em seguida foram moídas em moinho tipo Willey, com peneira de malha de $1 \mathrm{~mm}$ para posterior análises laboratoriais. As determinações do teor de matéria seca a $105^{\circ} \mathrm{C}$ foram realizadas segundo Silva \& Queiroz (2002). Os teores de proteína bruta (PB) foram estimados pela análise de nitrogênio total multiplicado pelo fator 6,25 (AOAC, 1995).

As determinações dos constituintes da fração fibrosa (FDN, FDA e lignina) foram realizadas pelo método de Goering \& Soest (1970) e a digestibilidade in vitro da matéria orgânica foi analisada segundo metodologia proposta por Tilley \& Terry (1963).
O cálculo dos teores de nutrientes da massa total dos pastos foi estimado, pela proporção de forrageira de inverno (FI) e de capim-Tifton 85(T-85), multiplicado pelo teor de nutriente estudado, em que $\%$ nutriente total $=\%$ FI x \% nutriente $+\% \mathrm{~T}-85 \times \%$ nutriente.

$\mathrm{O}$ delineamento experimental foi de blocos completos ao acaso, três repetições, e os dados experimentais submetidos à análise estatística pelo proc MIXED e medidas repetidas no tempo, segundo Littell et al. (1998), pelo programa estatístico SAS Institute (1990). Na obtenção das médias, foi utilizado o método dos quadrados mínimos e, o efeito de comparação de médias entre tratamentos, utilizou-se o teste $\mathrm{F}$, em nível de significância de $10 \%$.

\section{RESULTADOS E DISCUSSÃO}

Ocorreu interação significativa entre os pastos e os períodos de crescimento referente aos teores de proteína bruta (PB) da massa total em relação a aveia preta, e diferença significativa $(\mathrm{P}<0,1)$ nos teores médios de $\mathrm{PB}$ do capimTifton 85 avaliado nos períodos de crescimento (Tabela 1).

TABELA 1 - Teor de proteína bruta (\% MS) da massa total, da aveia preta e de capim-Tifton 85 exclusivo e sobressemeado, em duas épocas de semeadura.

\begin{tabular}{|c|c|c|c|c|c|c|}
\hline & \multicolumn{5}{|c|}{ Avaliações } & \multirow{2}{*}{ Média } \\
\hline & $1^{\mathbf{a}}$ & $2^{\mathrm{a}}$ & $3^{\mathrm{a}}$ & $4^{\mathrm{a}}$ & $5^{\mathbf{a}}$ & \\
\hline & \multicolumn{6}{|c|}{ Total } \\
\hline $\mathrm{AP}+\mathrm{M} \mathrm{E} 1$ & $16,2 \mathrm{ABa}$ & $9,1 \mathrm{Ab}$ & $7,7 \mathrm{Ac}$ & $7,6 \mathrm{BCc}$ & $7,9 \mathrm{Bc}$ & 9,7 \\
\hline $\mathrm{AP}+\mathrm{AG} \mathrm{E} 1$ & $16,2 \mathrm{ABa}$ & $9,9 \mathrm{Ab}$ & $7,4 \mathrm{Ac}$ & $7,0 \mathrm{Cc}$ & $7,3 \mathrm{BCc}$ & 9,6 \\
\hline $\mathrm{T}-85 \mathrm{E} 1$ & $14,2 \mathrm{Ba}$ & $10,4 \mathrm{Ab}$ & $7,0 \mathrm{Ac}$ & 7,7 BCc & $7,4 \mathrm{Bc}$ & 9,3 \\
\hline $\mathrm{AP}+\mathrm{M} \mathrm{E} 2$ & $17,2 \mathrm{Aa}$ & $11,1 \mathrm{Ab}$ & $7,7 \mathrm{Ad}$ & $10,1 \mathrm{Abc}$ & $9,0 \mathrm{Ac}$ & 11,0 \\
\hline $\mathrm{AP}+\mathrm{AGE} 2$ & $10,8 \mathrm{Ca}$ & $10,7 \mathrm{Aa}$ & $7,5 \mathrm{Ab}$ & $9,7 \mathrm{Aa}$ & $8,9 \mathrm{Aa}$ & 9,5 \\
\hline $\mathrm{T}-85 \mathrm{E} 2$ & $14,4 \mathrm{Ba}$ & $10,3 \mathrm{Ab}$ & $7,2 \mathrm{Ac}$ & $8,3 \mathrm{Bc}$ & $8,0 \mathrm{Abc}$ & 9,7 \\
\hline \multirow[t]{2}{*}{ Média } & 14,8 & 10,3 & 7,4 & 8,4 & 8,0 & \\
\hline & \multicolumn{6}{|c|}{ Aveia Preta } \\
\hline $\mathrm{AP}+\mathrm{M} \mathrm{E} 1$ & $16,9 \mathrm{Aa}$ & $9,7 \mathrm{Bb}$ & $7,7 \mathrm{Bb}$ & - & - & 11,4 \\
\hline $\mathrm{AP}+\mathrm{AGE} 1$ & $14,9 \mathrm{Ba}$ & $10,1 \mathrm{Bb}$ & $8,2 \mathrm{Bc}$ & - & - & 11,1 \\
\hline $\mathrm{AP}+\mathrm{M}$ E2 & $18,3 \mathrm{Aa}$ & $11,3 \mathrm{Bb}$ & $7,9 \mathrm{Bc}$ & - & - & 12,5 \\
\hline $\mathrm{AP}+\mathrm{AGE} 2$ & $14,9 \mathrm{Bb}$ & $19,2 \mathrm{Aa}$ & $10,7 \mathrm{Ac}$ & - & - & 14,9 \\
\hline \multirow[t]{2}{*}{ Média } & 16,3 & 12,6 & 8,6 & - & - & \\
\hline & \multicolumn{6}{|c|}{ Capim-Tifton 85} \\
\hline $\mathrm{AP}+\mathrm{M} \mathrm{E} 1$ & 16,7 & 9,5 & 8,7 & 8,4 & 7,3 & 10,1 \\
\hline $\mathrm{AP}+\mathrm{AG} \mathrm{E} 1$ & 16,7 & 10,5 & 8,6 & 8,0 & 7,7 & 10,3 \\
\hline $\mathrm{T}-85 \mathrm{E} 1$ & 14,5 & 11,1 & 8,2 & 7,7 & 6,8 & 9,8 \\
\hline $\mathrm{AP}+\mathrm{M} \mathrm{E} 2$ & 16,9 & 11,4 & 7,7 & 10,2 & 9,2 & 11,0 \\
\hline $\mathrm{AP}+\mathrm{AGE} 2$ & 15,1 & 13,0 & 7,6 & 9,8 & 9,1 & 10,9 \\
\hline $\mathrm{T}-85 \mathrm{E} 2$ & 15,6 & 10,5 & 7,3 & 8,3 & 8,2 & 10,0 \\
\hline Média & $15,9 \mathrm{a}$ & $11,0 \mathrm{~b}$ & $8,0 \mathrm{~d}$ & $8,7 \mathrm{c}$ & $8,2 \mathrm{~d}$ & \\
\hline
\end{tabular}

Médias seguidas de mesmas letras minúsculas, na linha e maiúsculas, na coluna não diferem entre si $(\mathrm{P}>0,1)$. Legenda: M: milheto; AP: aveia preta; AG: AG2501C; T-85: Capim-Tifton 85; E: época de semeadura. $1^{a}$ Avaliação: E1: 19-06 a 0608; E2: 02-07 a 19-08; 2a Avaliação: E1: 07-08 a 13-09; E2: 20-08 a 1-10; 3ª Avaliação: E1: 14-09 a 25-10, E2: 02-10 a 11-11; $4^{a}$ Avaliação: E1: 26-10 a 09-12, E2: 12-11 a 07-01; 5a Avaliação: E1: 10-12 a 15-01, E2: 08-01 a 11-02. 
Maiores teores de PB foram observados no primeiro período de crescimento no pasto de aveia preta + milheto E2 $(17,2 \%)$, não diferindo dos pastos de aveia preta + milheto E1 (16,2\%) e aveia preta + AG2501C E1 (16,2\%). Os maiores teores de $\mathrm{PB}$ observados na primeira avaliação ocorreram devido à presença de aveia preta no pasto.

Nas demais avaliações observou-se queda no teor de $\mathrm{PB}$, em virtude da baixa presença da aveia preta, que estava florescendo nesse período. Esses resultados são coerentes, pois, com a mudança da composição botânica, da estrutura de vegetação e da relação folha/colmo, houve alteração dos teores de PB com o decorrer das avaliações.

Os teores de PB do capim-Tifton 85 variaram com as avaliações, registrando-se maiores teores de PB no capim que cresceu no inverno. Esse fato pode ser explicado devido à maior porcentagem ocorrida de folhas do capim-
Tifton 85 colhido no inverno, comparado com as plantas que cresceram na primavera-verão, que possuíam no momento mais colmo. Cumpre destacar que, os teores de PB observados nas forrageiras colhidas nas diferentes épocas estão acima do valor mínimo de $7 \%$ preconizado por Minson (1990), ocorrendo suprimento adequado de $\mathrm{N}$ para os microrganismos ruminais, garantindo a mantença dos animais.

Nos teores de fibra insolúvel em detergente neutro (FDN) da massa total de forragem e dos componentes forrageiros em estudo (Tabela 2), nos pastos de capim-Tifton 85 exclusivo e sobressemeados, ocorreu diferença significativa $(\mathrm{P}<0,1)$ na interação entre os pastos e os períodos de crescimento, em relação aos teores de FDN da massa total de forragem e capim-Tifton 85.

TABELA 2 - Teor de fibra insolúvel em detergente neutro (\%) da massa total, da aveia preta e capim-Tifton 85 exclusivo e sobressemeado, em duas épocas de semeadura.

\begin{tabular}{|c|c|c|c|c|c|c|}
\hline & \multicolumn{5}{|c|}{ Avaliações } & \multirow{2}{*}{ Média } \\
\hline & $\mathbf{1}^{\mathbf{a}}$ & $2^{\mathrm{a}}$ & $3^{\mathrm{a}}$ & $4^{\mathrm{a}}$ & $5^{\mathrm{a}}$ & \\
\hline & \multicolumn{6}{|c|}{ Total } \\
\hline $\mathrm{AP}+\mathrm{M}$ E1 & $68,6 \mathrm{Ab}$ & $69,7 \mathrm{ABb}$ & $55,0 \mathrm{Bc}$ & $66,7 \mathrm{Bb}$ & $75,8 \mathrm{Ba}$ & 67,2 \\
\hline $\mathrm{AP}+\mathrm{AG} \mathrm{E} 1$ & $72,1 \mathrm{Aab}$ & $69,4 \mathrm{ABb}$ & $54,5 \mathrm{Bd}$ & $63,6 \mathrm{Bc}$ & $75,4 \mathrm{BCa}$ & 67,0 \\
\hline T-85 E1 & $73,8 \mathrm{Ab}$ & $67,0 \mathrm{Bc}$ & $53,7 \mathrm{Bd}$ & $64,7 \mathrm{Bc}$ & $77,3 \mathrm{Aa}$ & 67,3 \\
\hline $\mathrm{AP}+\mathrm{M} E 2$ & $65,9 \mathrm{Ac}$ & $71,5 \mathrm{ABb}$ & $66,0 \mathrm{Ac}$ & $72,1 \mathrm{Ab}$ & $75,8 \mathrm{Ba}$ & 70,2 \\
\hline $\mathrm{AP}+\mathrm{AG} \mathrm{E} 2$ & $54,5 \mathrm{Bd}$ & $61,3 \mathrm{Cc}$ & $69,9 \mathrm{Ab}$ & $74,8 \mathrm{Aa}$ & $73,0 \mathrm{Da}$ & 66,7 \\
\hline T-85 E2 & $67,8 \mathrm{Ac}$ & 73,7 Aab & $69,7 \mathrm{Ab}$ & 73,1 Aab & $74,3 \mathrm{CDa}$ & 71,7 \\
\hline \multirow[t]{2}{*}{ Média } & 67,1 & 68,8 & 61,5 & 69,2 & 75,3 & \\
\hline & \multicolumn{6}{|c|}{ Aveia preta } \\
\hline $\mathrm{AP}+\mathrm{M}$ E1 & 51,1 & 58,7 & 66,6 & - & - & 58,8 \\
\hline $\mathrm{AP}+\mathrm{AG} \mathrm{E} 1$ & 57,7 & 60,7 & 65,3 & - & - & 61,2 \\
\hline $\mathrm{AP}+\mathrm{M} \mathrm{E} 2$ & 50,6 & 62,6 & 64,6 & - & - & 59,3 \\
\hline $\mathrm{AP}+\mathrm{AG} \mathrm{E} 2$ & 57,7 & 55,3 & 60,6 & - & - & 57,9 \\
\hline \multirow[t]{2}{*}{ Média } & $54,3 \mathrm{c}$ & $59,3 \mathrm{~b}$ & $64,3 \mathrm{a}$ & - & - & \\
\hline & \multicolumn{6}{|c|}{ Capim-Tifton 85} \\
\hline $\mathrm{AP}+\mathrm{M}$ E1 & $74,4 \mathrm{Ab}$ & $74,3 \mathrm{Ab}$ & $62,3 \mathrm{Bd}$ & $74,0 \mathrm{ABb}$ & $80,0 \mathrm{Aa}$ & 73,0 \\
\hline $\mathrm{AP}+\mathrm{AG} \mathrm{E} 1$ & $76,1 \mathrm{Ab}$ & $73,7 \mathrm{ABc}$ & $62,6 \mathrm{Bd}$ & $72,8 \mathrm{Bc}$ & $79,6 \mathrm{ABa}$ & 73,0 \\
\hline T-85 E1 & $75,4 \mathrm{Ab}$ & $71,8 \mathrm{Bc}$ & $63,0 \mathrm{Bd}$ & $73,9 \mathrm{ABb}$ & $81,2 \mathrm{Aa}$ & 73,1 \\
\hline $\mathrm{AP}+\mathrm{M}$ E2 & $74,1 \mathrm{Ab}$ & $74,1 \mathrm{Ab}$ & $66,2 \mathrm{ABd}$ & $72,5 \mathrm{Bc}$ & $77,5 \mathrm{BCa}$ & 72,9 \\
\hline $\mathrm{AP}+\mathrm{AG} \mathrm{E} 2$ & $76,4 \mathrm{Aa}$ & $74,6 \mathrm{Aab}$ & $70,3 \mathrm{Ac}$ & $75,4 \mathrm{Aa}$ & $75,0 \mathrm{Cab}$ & 74,3 \\
\hline T-85 E2 & $73,5 \mathrm{Ab}$ & 74,9 Aab & $69,8 \mathrm{Ac}$ & $73,8 \mathrm{ABb}$ & $75,7 \mathrm{Ca}$ & 73,6 \\
\hline Média & 75,0 & 73,9 & 65,7 & 73,7 & 78,9 & \\
\hline
\end{tabular}

Médias seguidas de mesmas letras minúsculas, na linha e maiúsculas, na coluna não diferem entre si $(\mathrm{P}>0,1)$. Legenda: M: milheto; AP: aveia preta; AG: AG2501C; T-85: Capim-Tifton 85; E: época de semeadura. $1^{a}$ Avaliação: E1: 19-06 a 0608; E2: 02-07 a 19-08; 2a Avaliação: E1: 07-08 a 13-09; E2: 20-08 a 1-10; 3ª Avaliação: E1: 14-09 a 25-10, E2: 02-10 a 11-11; 4a Avaliação: E1: 26-10 a 09-12, E2: 12-11 a 07-01; 5a Avaliação: E1: 10-12 a 15-01, E2: 08-01 a 11-02.

Ciênc. agrotec., Lavras, v. 30, n. 2, p. 335-343, mar./abr., 2006 
Os teores de FDN da massa total de forragem nos pastos, na quinta avaliação, foram maiores $(\mathrm{P}<0,1) \mathrm{em}$ relação aos pastos avaliados anteriormente, nas duas épocas de semeadura. A presença da forrageira de inverno contribuiu, em geral, para o decréscimo dos teores de FDN na massa total de forragem (Tabela 2).

$\mathrm{O}$ teor de FDN da aveia preta (Tabela 2) aumentou significativamente $(\mathrm{P}<0,1)$ com o avanço dos períodos de crescimento do pasto $(54,3 ; 59,3$ e $64,3 \%$, respectivamente).

O capim-Tifton 85 exclusivo apresentou teores mais elevados de FDN quando comparado com as forrageiras de inverno e na mistura total. Ressalta-se que elevados valores de FDN no capim-Tifton 85 são características deste capim (GOMIDE, 1996; HILL et al., 1996). No entanto, apresentam teores de lignina relativamente baixos, conferindo qualidade, evidenciada nos ganhos de peso dos animais que consomem essa forragem (PEDREIRA \& MELLO, 2000).

A proporção de FDN na forrageira é importante também pelo fato desta estar relacionada com o consumo máximo de matéria seca, quando situa-se na faixa de 5560\% na base da matéria seca (MERTENS, 1994).

Ocorreu interação significativa entre os pastos e os períodos de crescimento na massa total do pasto e nos componentes, forrageira de inverno e capim-Tifton 85 , nos teores de fibra insolúvel em detergente ácido (FDA) (Tabela 3).

TABELA 3 - Teor de fibra insolúvel em detergente ácido (\%) da massa total, aveia preta e capim-Tifton 85 exclusivo e sobressemeado.

\begin{tabular}{|c|c|c|c|c|c|c|}
\hline & \multicolumn{5}{|c|}{ Avaliações } & \multirow{2}{*}{ Média } \\
\hline & $\mathbf{1}^{\mathbf{a}}$ & $2^{-\mathbf{a}}$ & $3^{\mathbf{a}^{3}}$ & $4^{\mathrm{a}}$ & $5^{\mathbf{a}}$ & \\
\hline & \multicolumn{6}{|c|}{ Total } \\
\hline $\mathrm{AP}+\mathrm{M} \mathrm{E} 1$ & $35,1 \mathrm{Bc}$ & $35,1 \mathrm{Ba}$ & $43,2 \mathrm{Aa}$ & $36,6 \mathrm{Ac}$ & $40,6 \mathrm{Bb}$ & 38,1 \\
\hline $\mathrm{AP}+\mathrm{AG} \mathrm{E} 1$ & $43,1 \mathrm{Aa}$ & $42,3 \mathrm{Aa}$ & $37,1 \mathrm{BCb}$ & $34,7 \mathrm{ABc}$ & $40,5 \mathrm{Ba}$ & 39,5 \\
\hline $\mathrm{T}-85 \mathrm{E} 1$ & $43,0 \mathrm{Aa}$ & $40,9 \mathrm{Aa}$ & $35,1 \mathrm{Cb}$ & $34,8 \mathrm{ABb}$ & $42,1 \mathrm{Aa}$ & 39,2 \\
\hline $\mathrm{AP}+\mathrm{M}$ E2 & $38,1 \mathrm{ABbc}$ & $40,7 \mathrm{Aab}$ & $42,0 \mathrm{ABa}$ & $37,5 \mathrm{Ac}$ & $39,0 \mathrm{Cbc}$ & 39,5 \\
\hline $\mathrm{AP}+\mathrm{AGE} 2$ & $29,0 \mathrm{Ce}$ & $33,3 \mathrm{Bd}$ & $43,3 \mathrm{Aa}$ & $37,6 \mathrm{Ac}$ & $40,0 \mathrm{BCb}$ & 36,6 \\
\hline $\mathrm{T}-85 \mathrm{E} 2$ & 40,6 Aab & $43,2 \mathrm{Aa}$ & 41,7 ABab & $33,7 \mathrm{Bc}$ & $40,2 \mathrm{Bb}$ & 39,9 \\
\hline \multirow[t]{2}{*}{ Média } & 38,1 & 39,3 & 40,4 & 35,8 & 40,4 & \\
\hline & \multicolumn{6}{|c|}{ Aveia preta } \\
\hline $\mathrm{AP}+\mathrm{M} \mathrm{E} 1$ & $32,8 \mathrm{Aa}$ & $32,8 \mathrm{Aa}$ & $29,8 \mathrm{Bb}$ & - & - & 31,8 \\
\hline $\mathrm{AP}+\mathrm{AG} \mathrm{E} 1$ & $33,3 \mathrm{Aa}$ & $32,3 \mathrm{Aa}$ & $28,1 \mathrm{Bb}$ & - & - & 31,6 \\
\hline $\mathrm{AP}+\mathrm{M}$ E2 & $30,8 \mathrm{Ba}$ & $31,2 \mathrm{ABa}$ & $32,0 \mathrm{Aa}$ & - & - & 31,3 \\
\hline $\mathrm{AP}+\mathrm{AGE} 2$ & $33,3 \mathrm{Aa}$ & $30,8 \mathrm{Bb}$ & $31,8 \mathrm{Ab}$ & - & - & 31,7 \\
\hline \multirow[t]{2}{*}{ Média } & 32,5 & 32,0 & 30,7 & - & - & \\
\hline & \multicolumn{6}{|c|}{ Capim-Tifton 85} \\
\hline $\mathrm{AP}+\mathrm{M}$ E1 & $36,9 \mathrm{Dd}$ & $35,9 \mathrm{Cd}$ & $49,1 \mathrm{Aa}$ & $40,6 \mathrm{Ac}$ & $42,9 \mathrm{ABb}$ & 41,3 \\
\hline $\mathrm{AP}+\mathrm{AG} \mathrm{E} 1$ & $45,3 \mathrm{Aa}$ & $46,3 \mathrm{Aa}$ & $44,2 \mathrm{Bab}$ & $39,7 \mathrm{Ac}$ & $42,8 \mathrm{ABb}$ & 43,5 \\
\hline T-85 E1 & $43,9 \mathrm{ABCa}$ & $42,9 \mathrm{ABa}$ & $41,2 \mathrm{Bab}$ & $39,7 \mathrm{Ab}$ & $44,3 \mathrm{Aa}$ & 42,6 \\
\hline $\mathrm{AP}+\mathrm{M}$ E2 & $42,7 \mathrm{BCa}$ & $43,7 \mathrm{ABa}$ & $42,1 \mathrm{Bab}$ & $37,7 \mathrm{Ac}$ & $40,0 \mathrm{Cb}$ & 41,0 \\
\hline $\mathrm{AP}+\mathrm{AGE} 2$ & $40,6 \mathrm{Cab}$ & 39,6 Bab & $43,5 \mathrm{Ba}$ & $37,9 \mathrm{Ab}$ & $41,0 \mathrm{BCa}$ & 40,7 \\
\hline $\mathrm{T}-85 \mathrm{E} 2$ & $44,0 \mathrm{ABa}$ & $45,0 \mathrm{Aa}$ & $41,8 \mathrm{Bab}$ & $34,0 \mathrm{Bc}$ & $40,9 \mathrm{Cb}$ & 40,9 \\
\hline Média & 42,2 & 42,2 & 43,7 & 38,3 & 42,0 & \\
\hline
\end{tabular}

Médias seguidas de mesmas letras minúsculas, na linha e maiúsculas, na coluna não diferem entre si (P>0,1). Legenda: M: milheto; AP: aveia preta; AG: AG2501C; T-85: Capim-Tifton 85; E: época de semeadura. 1a Avaliação: E1: 19-06 a 0608; E2: 02-07 a 19-08; 2a Avaliação: E1: 07-08 a 13-09; E2: 20-08 a 1--10; 3a Avaliação: E1: 14-09 a 25-10, E2: 02-10 a 11-11; 4a Avaliação: E1: 26-10 a 09-12, E2: 12-11 a 07-01; 5a Avaliação: E1: 10-12 a 15-01, E2: 08-01 a 11-02. 
Os menores teores de FDA da massa total de forragem, no primeiro período de crescimento, foram observados no pasto de aveia preta + AG2501C E2 (29,0\%). Nos demais períodos de crescimento em relação à massa total de forragem na primeira e segunda épocas de semeadura, observou-se variação dos teores de FDA em virtude da composição botânica presente em cada avaliação.

Nos teores de FDA do componente forrageira de inverno (Tabela 3), ocorreu diferença significativa entre os pastos, no primeiro período de crescimento, quando o menor teor foi observado na forragem de aveia preta + milheto E2 (30,8\%). Quanto aos períodos de crescimento, maiores teores de FDA foram obtidos nos pastos de aveia preta + milheto E1 e aveia preta + AG2501C E1, na primeira e segunda avaliações.

Os valores de FDA do capim-Tifton 85 avaliados nos diferentes pastos e diferentes períodos de crescimento apresentaram variações de 38,3 a 43,7\%. Tal fato pode ser explicado pelas mudanças estruturais na parede celular no decorrer das estações devido à alteração de temperatura. Essa variação também pode ser atribuída à necessidade de materiais estruturais na sustentação da planta durante o seu desenvolvimento.

Para os resultados referentes aos teores de lignina (Tabela 4) ocorreu interação significativa entre os pastos e períodos de crescimento na massa total do pasto e nos componentes forrageira de inverno e capim-Tifton 85 .

TABELA 4 - Teor de lignina (\%) da massa total, da aveia preta e do capim-Tifton 85 exclusivo e sobressemeado, em duas épocas de semeadura.

\begin{tabular}{|c|c|c|c|c|c|c|}
\hline & \multicolumn{5}{|c|}{ Avaliações } & \multirow{2}{*}{ Média } \\
\hline & $1^{\mathbf{a}}$ & $2^{\mathbf{a}}$ & $3^{\mathbf{a}}$ & $4^{\mathbf{a}}$ & $5^{\mathbf{a}}$ & \\
\hline & \multicolumn{6}{|c|}{ Total } \\
\hline $\mathrm{AP}+\mathrm{M}$ E1 & $4,5 \mathrm{Cb}$ & $5,6 \mathrm{Aa}$ & $4,7 \mathrm{BCab}$ & $4,6 \mathrm{Bb}$ & $5,3 \mathrm{ABa}$ & 4,9 \\
\hline $\mathrm{AP}+\mathrm{AG} \mathrm{E} 1$ & 4,9 BCab & $5,1 \mathrm{ABa}$ & $4,4 \mathrm{Cb}$ & 4,8 $\mathrm{Bab}$ & $5,4 \mathrm{ABa}$ & 4,9 \\
\hline T-85 E1 & $5,9 \mathrm{Aa}$ & 4,7 Cbc & 4,6 BCc & 4,9 Bbc & $5,2 \mathrm{ABb}$ & 5,1 \\
\hline $\mathrm{AP}+\mathrm{M}$ E2 & $5,2 \mathrm{Babc}$ & $4,8 \mathrm{BCbc}$ & 5,3 Aab & $4,6 \mathrm{Bc}$ & $5,5 \mathrm{Aa}$ & 5,1 \\
\hline $\mathrm{AP}+\mathrm{AGE} 2$ & 4,8 BCab & $4,5 \mathrm{Cb}$ & $5,2 \mathrm{ABa}$ & $4,5 \mathrm{Bb}$ & $4,8 \mathrm{Bab}$ & 4,8 \\
\hline T-85 E2 & $5,2 \mathrm{Ba}$ & $5,5 \mathrm{Aa}$ & $5,6 \mathrm{Aa}$ & $5,6 \mathrm{Aa}$ & $3,4 \mathrm{Cb}$ & 5,1 \\
\hline \multirow[t]{2}{*}{ Média } & 5,1 & 5,0 & 5,0 & 4,8 & 4,9 & \\
\hline & \multicolumn{6}{|c|}{ Aveia Preta } \\
\hline $\mathrm{AP}+\mathrm{M}$ E1 & $2,7 \mathrm{Ab}$ & $4,6 \mathrm{Ba}$ & $5,3 \mathrm{Aa}$ & - & - & 4,4 \\
\hline $\mathrm{AP}+\mathrm{AG} \mathrm{E} 1$ & $2,7 \mathrm{Ac}$ & $5,6 \mathrm{Aa}$ & $4,6 \mathrm{Ab}$ & - & - & 4,3 \\
\hline $\mathrm{AP}+\mathrm{M}$ E2 & $2,2 \mathrm{Ac}$ & $3,3 \mathrm{Cb}$ & $5,0 \mathrm{Aa}$ & - & - & 3,5 \\
\hline $\mathrm{AP}+\mathrm{AGE} 2$ & $2,7 \mathrm{Ab}$ & $2,8 \mathrm{Cb}$ & $4,2 \mathrm{Aa}$ & - & - & 3,2 \\
\hline \multirow[t]{2}{*}{ Média } & 2,6 & 4,1 & 4,8 & - & - & \\
\hline & \multicolumn{6}{|c|}{ Capim-Tifton 85} \\
\hline $\mathrm{AP}+\mathrm{M}$ E1 & $5,0 \mathrm{Cb}$ & $6,0 \mathrm{Aa}$ & $5,3 \mathrm{ABb}$ & $5,1 \mathrm{BCb}$ & 5,5 Aab & 5,4 \\
\hline $\mathrm{AP}+\mathrm{AG} \mathrm{E} 1$ & 5,3 Cab & $5,3 \mathrm{BCab}$ & $5,1 \mathrm{Bb}$ & 5,5 ABab & $5,7 \mathrm{Aa}$ & 5,4 \\
\hline T-85 E1 & $6,1 \mathrm{ABa}$ & $5,0 \mathrm{Cc}$ & $5,4 \mathrm{ABbc}$ & 5,5 ABab & 5,5 Aabc & 5,5 \\
\hline $\mathrm{AP}+\mathrm{M}$ E2 & $6,4 \mathrm{ABa}$ & $5,0 \mathrm{Ccd}$ & $5,3 \mathrm{ABbc}$ & 4,7 CDd & $5,7 \mathrm{Ab}$ & 5,4 \\
\hline $\mathrm{AP}+\mathrm{AGE} 2$ & $6,8 \mathrm{Aa}$ & $5,5 \mathrm{BCb}$ & $5,2 \mathrm{ABb}$ & $4,5 \mathrm{Dc}$ & $5,0 \mathrm{Bc}$ & 5,4 \\
\hline T-85 E2 & $5,7 \mathrm{BCa}$ & 5,6 ABab & 5,6 Aab & 5,7 Aab & $3,5 \mathrm{Cb}$ & 5,2 \\
\hline Média & 5,9 & 5,4 & 5,3 & 5,2 & 5,1 & \\
\hline
\end{tabular}

Médias seguidas de mesmas letras minúsculas, na linha e maiúsculas, na coluna não diferem entre si (P>0,1). Legenda: M: milheto; AP: aveia preta; AG: AG2501C; T-85: Capim-Tifton 85; E: época de semeadura. 1a Avaliação: E1: 19-06 a 0608; E2: 02-07 a 19-08; 2a Avaliação: E1: 07-08 a 13-09; E2: 20-08 a 1o-10; 3a Avaliação: E1: 14-09 a 25-10, E2: 02-10 a 11-11; 4a Avaliação: E1: 26-10 a 09-12, E2: 12-11 a 07-01; 5a Avaliação: E1: 10-12 a 15-01, E2: 08-01 a 11-02.

Ciênc. agrotec., Lavras, v. 30, n. 2, p. 335-343, mar./abr., 2006 
Os teores de lignina da mistura total variaram de 3,4 a 5,9\% em função do período de crescimento, da espécie de forrageiras utilizadas e da composição botânica presente no momento da avaliação. $\mathrm{O}$ teor de lignina variou de $4,4 \%$, no pasto de aveia preta + AG2501C E1 (terceira avaliação), a 5,9\%, no pasto de Tifton-85 exclusivo E1 (primeira avaliação). A variação ocorreu devido à composição botânica presente na avaliação e também à época de semeadura, que interferiu nos teores de lignina.

Variações no teor de lignina foram obtidas tanto na forrageira de inverno (2,2 a 5,3\%) como do componente capim-Tifton 85 (4,5 a 6,8\%), que receberam ou não sobressemeadura nos diferentes períodos de crescimento.

Para a digestibilidade in vitro da matéria orgânica (DIVMO), verificou-se interação significativa entre os pastos e os períodos de crescimento referente aos dados de digestibilidade na mistura total e na aveia preta (Tabela 5). No componente capim-Tifton 85, ocorreu diferença significativa $(\mathrm{P}<0,1)$ nos valores médios em função das avaliações.

Observa-se que, nas duas primeiras avaliações, na mistura total e nos componentes (aveia preta e capim-Tifton 85), os valores de DIVMO foram mais elevados quando comparados com as demais (Tabela 5). Tanto a forrageira de inverno quanto o capim-Tifton 85 contribuíram melhorando a digestibilidade da forragem nessa época crítica de crescimento. À medida que a aveia preta foi florescendo e diminuindo sua presença na composição botânica, no terceiro período de crescimento, devido à maturidade fisiológica e ao alongamento do colmo, houve, em todas os pastos avaliados, queda na DIVMO (Tabela 5). Da mesma foram, Roso et al. (1999) não encontraram diferença na DIVMO,

TABELA 5 - Digestibilidade in vitro da matéria orgânica (\%) da massa total, aveia preta e capim-Tifton 85 exclusivo e sobressemeado, em duas épocas de semeadura.

\begin{tabular}{|c|c|c|c|c|c|c|}
\hline & \multicolumn{5}{|c|}{ Avaliações } & \multirow{2}{*}{ Média } \\
\hline & $\mathbf{1}^{\mathbf{a}}$ & $2^{\mathbf{a}}$ & $3^{\mathbf{a}}$ & $4^{\mathrm{a}}$ & $5^{-\mathbf{a}}$ & \\
\hline & \multicolumn{6}{|c|}{ Total } \\
\hline $\mathrm{AP}+\mathrm{M}$ E1 & $69,3 \mathrm{Aa}$ & $61,0 \mathrm{ABb}$ & $50,2 \mathrm{Bc}$ & $50,8 \mathrm{Bc}$ & $52,0 \mathrm{Bc}$ & 56,6 \\
\hline $\mathrm{AP}+\mathrm{AG} \mathrm{E} 1$ & $71,8 \mathrm{Aa}$ & $56,3 \mathrm{Bb}$ & $49,9 \mathrm{Bc}$ & $52,1 \mathrm{Bbc}$ & $53,4 \mathrm{Bbc}$ & 56,7 \\
\hline T-85 E1 & $65,1 \mathrm{ABa}$ & $55,5 \mathrm{BCb}$ & $50,2 \mathrm{Bb}$ & $51,1 \mathrm{Bb}$ & $52,4 \mathrm{Bb}$ & 54,9 \\
\hline $\mathrm{AP}+\mathrm{M}$ E2 & $71,0 \mathrm{Aa}$ & $58,5 \mathrm{ABb}$ & $55,8 \mathrm{Ac}$ & $57,6 \mathrm{Ac}$ & $54,6 \mathrm{Bc}$ & 59,5 \\
\hline $\mathrm{AP}+\mathrm{AG} \mathrm{E} 2$ & $69,3 \mathrm{Aa}$ & $69,0 \mathrm{Aa}$ & 58,7 Aab & $60,2 \mathrm{Aa}$ & $54,8 \mathrm{ABb}$ & 62,4 \\
\hline T-85 E2 & $61,8 \mathrm{Ba}$ & 63,8 Aa & $57,1 \mathrm{Ab}$ & $55,5 \mathrm{Abc}$ & $57,5 \mathrm{Ab}$ & 59,2 \\
\hline \multirow[t]{2}{*}{ Média } & 68,0 & 60,6 & 53,6 & 54,5 & 54,1 & \\
\hline & \multicolumn{6}{|c|}{ Aveia preta } \\
\hline $\mathrm{AP}+\mathrm{M}$ E1 & $80,0 \mathrm{Aa}$ & $70,3 \mathrm{Cb}$ & $63,4 \mathrm{Cc}$ & - & - & 71,2 \\
\hline $\mathrm{AP}+\mathrm{AG} \mathrm{E} 1$ & $77,9 \mathrm{Aa}$ & $75,0 \mathrm{Ba}$ & $65,8 \mathrm{BCb}$ & - & - & 72,9 \\
\hline $\mathrm{AP}+\mathrm{M} \mathrm{E} 2$ & $80,2 \mathrm{Aa}$ & $78,9 \mathrm{Aa}$ & $71,9 \mathrm{Bb}$ & - & - & 77,0 \\
\hline $\mathrm{AP}+\mathrm{AGE} 2$ & 77,9 Aa & $77,8 \mathrm{ABa}$ & $78,6 \mathrm{Aa}$ & - & - & 78,1 \\
\hline \multirow[t]{2}{*}{ Média } & 79,0 & 75,5 & 69,9 & - & - & \\
\hline & \multicolumn{6}{|c|}{ Capim-Tifton 85} \\
\hline $\mathrm{AP}+\mathrm{M} \mathrm{E} 1$ & 70,5 & 63,0 & 56,7 & 56,4 & 54,8 & 60,3 \\
\hline $\mathrm{AP}+\mathrm{AG} \mathrm{E} 1$ & 72,1 & 57,8 & 56,7 & 59,8 & 56,3 & 60,5 \\
\hline T-85 E1 & 66,6 & 59,5 & 58,9 & 58,2 & 55,1 & 59,7 \\
\hline $\mathrm{AP}+\mathrm{M}$ E2 & 71,5 & 58,1 & 56,0 & 57,8 & 55,8 & 59,8 \\
\hline $\mathrm{AP}+\mathrm{AG} \mathrm{E} 2$ & 69,4 & 60,0 & 59,0 & 60,6 & 56,2 & 61,0 \\
\hline T-85 E2 & 66,9 & 65,0 & 57,3 & 56,0 & 58,6 & 60,7 \\
\hline Média & $69,5 \mathrm{a}$ & $60,6 \mathrm{~b}$ & $57,4 \mathrm{c}$ & $58,2 \mathrm{c}$ & $58,1 \mathrm{c}$ & \\
\hline
\end{tabular}

Médias seguidas de mesmas letras minúsculas, na linha e maiúsculas, na coluna não diferem entre si (P>0,1). Legenda: M: milheto; AP: aveia preta; AG: AG2501C; T-85: Capim-Tifton 85; E: época de semeadura. 1a Avaliação: E1: 19-06 a 0608; E2: 02-07 a 19-08; 2a Avaliação: E1: 07-08 a 13-09; E2: 20-08 a 1o-10; 3a Avaliação: E1: 14-09 a 25-10, E2: 02-10 a 11-11; 4 Avaliação: E1: 26-10 a 09-12, E2: 12-11 a 07-01; 5a Avaliação: E1: 10-12 a 15-01, E2: 08-01 a 11-02. 
nos primeiros períodos de pastejo, trabalhando com aveia + azevém e triticale + azevém.

A redução no valor nutritivo da forragem, com o avanço no ciclo de desenvolvimento das plantas, é explicada pelo aumento da parede celular (BLASER, 1964), pela redução na relação folha/colmo e pelo aumento no percentual de material morto (ROSO et al., 2000).

Com relação à composição da aveia preta estudada, os valores de DIVMO diminuíram em função dos períodos de crescimento, em virtude do florescimento observado com o decorrer das avaliações, sendo que, na terceira avaliação, os materiais já estavam em florescimento e com maior proporção de caule.

Os valores de DIVMO do capim-Tifton 85 avaliados nos diferentes pastos e períodos de crescimento apresentaram pequenas variações nos três últimos períodos de crescimento. Esses valores foram menores quando comparados com os encontrados nas duas primeiras avaliações. Essa alteração ocorreu devido às mudanças estruturais na parede celular, maiores valores de FDN (Tabela 2) e lignina (Tabela 4), ao comparar os dados do quarto e do quinto períodos de avaliação. Pode ser observado também, no mesmo período de crescimento queda no teor de PB (Tabela 1). Segundo Soest (1994), a queda da digestibilidade nas forrageiras, com o avanço da maturidade, está associada ao aumento dos constituintes da parede celular, principalmente da lignina, além da diminuição na relação lâmina/colmo e teor de PB, conforme constatado no presente trabalho.

\section{CONCLUSÃO}

O valor nutritivo do capim-Tifton 85 exclusivo ou sobressemeado com gramíneas anuais de inverno e de verão diminuiu nas avaliações de primavera/verão em função das alterações na composição botânica e dos aspectos morfológicos dos pastos.

\section{REFERÊNCIAS BIBLIOGRÁFICAS}

ANDRIOLI, I.; CENTURION, J. F. Levantamento detalhado dos solos da Faculdade de Ciências Agrárias e Veterinárias de Jaboticabal. In: CONGRESSO BRASILEIRO DE CIÊNCIA DO SOLO, 27., 1999, Brasília, DF. Anais... Brasília, DF: Sociedade Brasileira de Ciência do Solo, 1999. p. 32.

ASSOCIATION OF OFFICIAL ANALYTICAL CHEMISTS. Micro Kjeldahl method. In: CUNNIF, P. (Ed.). Official methods on analysis of AOAC International. Arlington: AOAC, 1995. cap. 12, p. 7.
BLASER, R. E. Symposium on forage utilization: effects of fertility levels and stage of maturity on forage nutritive value. Journal Animal Science, Champaign, v. 23, n. 1, p. 246-253, 1964.

GOERING, N. K.; SOEST, P. J. van. Forage fiber analysis: apparatus, reagents, procedures and some application. Washington: USDA, 1970. 20 p. (Agriculture Handbook).

GOMIDE, C. C. C. Algumas características fisiológicas e químicas de cinco cultivares de Cynodon. 1996. Dissertação (Mestrado em Zootecnia) - Faculdade de Ciências Agrárias e Veterinárias, Universidade Estadual Paulista, Jaboticabal, 1996.

HILL, G. M.; NEWTON, G. L.; STREETER, M. N. Digestibility and utilization of pearl millet diets fed to finishing beef cattle. Journal Animal Science, Champaign, v. 74, p. 1728-1735, 1996.

LITTELL, R. C.; HENRY, P. R.; AMMERMAN, C. B. Statistical analysis of repeated measures data using SAS procedures. Journal Animal Science, Champaign, v. 76, n. 4, p. 1216-1231, 1998.

LUPATINI, G. C. Pastagens cultivadas de inverno para recria e terminação de bovinos. In: EFICIÊNCIA NA PRODUÇÃO DE BOVINOS DE CORTE, 2000, Santa Maria, RS. Anais... Santa Maria: UFSM, 2000, p. 9-35.

MERTENS, D. R. Regulation of forage intake. In: FAHEY JUNIOR, G. C.; COLLINS, M.; MERTENS, D. R. (Eds.). Forage quality, evaluation and utilization. Madison: ASA; CSSA; SSSA, 1994. p. 450-493.

MINSON, D. J. Forage in ruminant nutrition. New York: Academic, 1990. 483 p.

PEDREIRA, C. G. S.; MELLO, A. C. L. Cynodon spp.: a planta forrageira no sistema de produção. In: SIMPÓSIO SOBRE MANEJO DA PASTAGEM, 17., 2000, Piracicaba. Anais... Piracicaba: FEALQ, 2000. p. 109-134.

REIS, R. A.; SOLLENBERGER, L. E.; URBANO, D. Impact of overseeding cool-season annual forages on spring regrowth of Tifton 85 bermudagrass. In: INTERNATIONAL GRASSLAND CONGRESS, 19., 2001, São Pedro. Proceedings... São Pedro: Brazilian Society of Animal Husbandry, 2001. p. 295-297. 
ROSO, C.; RESTLE, J.; SOARES, A. B. Aveia preta, triticale e centeio em mistura com azevém: dinâmica, produção e qualidade de forragem. Revista Brasileira Zootecnia, Viçosa, v. 29, n. 1, p. 75-84, 2000.

ROSO, C.; RESTlE, J.; SOARES, A. B. Produção e qualidade de forragem da mistura de gramíneas anuais de estação fria sob pastejo contínuo. Revista Brasileira Zootecnia, Viçosa, v. 28, n. 3, p. 459-467, 1999.

SAS INSTITUTE. SAS/STAT user's guide. Versão 6.4. Cary, 1990. 846 p.

SILVA, D. J.; QUEIRÓZ, A. C. Análise de alimentos métodos químicos e biológicos. 3. ed. Viçosa: UFV, 2002. 235 p.
SOEST, P. J. Nutritional ecology of the ruminant. New York: Comstock, 1994. 476 p.

TILLEY, J. M. A.; TERRY, R. A. A two-stage technique for the "in vitro" digestion of forage crops. Journal British Grassland Society, Hurley, v. 18, n. 2, p. 104$111,1963$.

ZAGO, C. P.; RIBAS, P. M. AG 2501-C: novo híbrido forrageiro de sorgo x capim Sudão, para corte e pastejo. In: REUNIÃO ANUAL DA SOCIEDADE BRASILEIRA DE ZOOTECNIA, 26., 1989, Porto Alegre. Anais... Porto Alegre: SBZ, 1989. p. 142. 